\title{
Cesarean Section in Cattle: A Review
}

\author{
Devender Kumar, Satish, Govind Narayan Purohit
}

10.18805/ag.R-1933

\begin{abstract}
Cesarean section is one of the oldest surgical procedure performed on cows for delivery of the fetus at parturition. Depending upon the health status of dam and fetus cesarean section has been classified as emergency, non emphysematous and emphysematous procedure. The common maternal indications for performing cesarean section include pelvic fractures, cervical dilation failure and uncorrectable uterine torsion whereas the fetal indication include oversized fetuses and maldisposed calves. Many anesthetic protocols are available for cow however, most cesarean section in cattle can be satisfactorily performed under mild sedation and local infiltration anesthesia using $2 \%$ lidocaine. Operative sites for cesarean section in cattle include right and left flank, midline, paramedian, parammary and oblique ventrolateral. The choice of operative sites depends upon facility and patient condition. Peri-operative (before, during and after the operation) care appears to be of utmost significance, post-operative complications of cesarean section include peritonitis, seroma formation, hernia and poor fertility. On the successful outcome of cesarean section in cows in terms of dam and calf survival and future fertility of cows underdoing cesarean section. Previous handling, delay in presentation to referral centers results in poor outcome and thus animal owners must be explained the benefits of prompt presentation of cow to cesarean section for optimal benefits.
\end{abstract}

Key words: Cesarean section, Cattle.

Cesarean section is one of the oldest surgical procedure performed in veterinary medicine and involves the removal of calf near parturition by lapro-hysterotomy. While a number of sites have been described for surgery the choice of operative site depends upon the condition of the cow, presence of a live/dead and /or emphysematous fetus which also determine the outcome of surgery. Most cesarean sections in cows can be satisfactory performed under local infiltration anesthesia with mild sedation. Perioperative care (before, during and after surgery) seems to be of utmost significance in deciding the outcome of surgery. The history, operative sites, anesthesia, operative procedure post operative care and future fertility of cesarean section in cows are described in this review.

\section{Cesarean section (Laparo-hysterotomy) in animals}

Veterinarians of the 19th century performed caesarean sections, usually on small animals, but the procedure was performed on cattle only sporadically before World War II (Drife, 2002). By 1950s, however, caesarean became commonplace in cows (Gendreau, 1947; Bronislawski, 1950; Tharp et al., 1951; Lensch, 1958) and ewes (Newlyn and Mostyn, 1950).

\section{Operative techniques}

Cesarean section is one of the oldest surgical procedures in human and veterinary medicine and refers to the surgical delivery of the fetus at or around parturition by laparohysterotomy (laparotomy also known as celiotomy). It has been reviewed that dairy practices perform fewer cesarean sections, but these occur year round. In contrast, cesarean sections in beef practice are numerous and heavily concentrated during the late winter and early spring
Department of Veterinary Gynaecology and Obstetrics, Rajasthan University of Veterinary and Animal Sciences, Bikaner-302 004, Rajasthan, India.

Corresponding Author: Devender Kumar, Department of Veterinary Gynaecology and Obstetrics, Rajasthan University of Veterinary and Animal Sciences, Bikaner-302 004, Rajasthan, India. Email: dr.devenderkumarsuthar@gmail.com

How to cite this article: Kumar, D., Satish, and Purohit, G.N. (2021). Cesarean Section in Cattle: A Review. Agricultural Reviews. DOI: 10.18805/ag.R-1933.

Submitted: 20-08-2019 Accepted: 02-08-2021 Online: 08-09-2021

(Newman and Anderson, 2005). Numerous variables determine whether the procedure is successful. The most important is the health status of the dam and calf at the time of surgery. For this reason, cesarean section has been categorized as elective (Sloss and Dufty, 1977), emergency (nonemphysematous), or emphysematous procedures (Newman and Anderson, 2005).

\section{Indications}

Maternal factor-Maternal and fetal indications for performing a cesarean section. Maternal indications include immature heifers, pelvic deformities and failure of cervical dilation, uncorrectable uterine torsion, uterine tear, hydrops and prepartum paralysis (Dubay, 1987; Campbell and Fubini, 1990; Frazer et al., 1996; Purohit and Mehta, 2006; Purohit et al., 2006; Ravinder et al., 2008, Purohit et al., 2013). Beef breeds that have double muscling (which is regarded as a desirable beef characteristic) such as Charolais, Limousin, South Devon and Belgian Blue breeds frequently require cesarean section (Kolkman et al., 2007; Kolkman et al., 2010). 
Risk factors in cattle are increased by heifer's age less than 2 years, long gestation period, preceding long interval from first service to conception, long dry period, double-muscled or Piedmont sire and previous cesarean section calving (Barkema et al., 1992a; Kolkman et al., 2007). Smaller (ver-sus larger) pelvic area increases the risk of dystocia at parturition for dairy and beef cattle and hences the chances of cesarean section ( Heiw et al.,2016). One study showed that the ratio of calf birth weight to maternal intrapelvic area or body weight was positively associated with calving difficulty score (Nogalski and Mordas 2012).

\section{Fetal factor}

Fetal indicators for cesarean section include normal and pathologic fetal conditions (Purohit et al., 2011b). Normal fetal conditions consist of absolute fetal oversize (relative to a normal maternal pelvis size) and malposition. A highvalue calf, such as an embryo transfer or clone, may be an indication for an elective cesarean section. Pathologic fetal conditions include fetal anasarca, schistosomus reflexus, hydrocephalus, conjoined twins, emphysematous fetus, mummification and prolonged gestation (Campbell and Fubini, 1990; Purohit, 2006; Purohit et al., 2006a; Purohit et al., 2006b). An unusual fetal indication for cesarean section could be the recovery of gnotobiotic calves for research. Depending on the circumstances, including the availability of a fetatome and the practitioner's experience, a fetotomy is not always a viable option. Attempting a fetotomy on an emphysematous fetus when the uterus is tightly contracted, little uterine fluid is present, cervix is incompletely dilated, or uterus is friable is inadvisable (Campbell and Fubini, 1990). Fetotomy also is not recommended on a downer cow, necessitating a cesarean section. In practice, caesarean section is sometimes opted when all other procedures for relieving dystocia have failed. Distinctly five reasons have been described to account for $90 \%$ of all caesarean sections and these are a) Fetal oversize, b)incomplete cervical dilation, c) irreducible uterine torsion, d) fetal deformity and e) fetal maldispositions (Pearson, 1999). In beef cattle, the calf is the primary return on investment compared with dairy cattle and buffaloes, in which the animal's milk production is often valued greater than calf survival. Beef clients may be more likely to seek veterinary attention sooner compared with dairy clients (Kolkman et al., 2010). For these reasons, it is an impression that more positive outcomes occur with beef cattle cesarean sections compared with dairy cattle cesarean sections (Newman and Anderson, 2005). An uncorrectable uterine torsion is a frequent indication for cesarean section in the buffalo (Purohit and Mehta, 2006). In a retrospective analysis of 192 cases of dystocia in cattle and 112 cases in buffalo, fetal causes were predominant $(65.62 \%)$ in cows (Purohit et al., 2011c).

\section{Restraint and Anesthesia}

The restraint of the animal depends upon the operative site being used to perform the operation. When a standing flank laparotomy is to be performed, cows are restrained in a chute. Whereas, when the approach is midline, paramedian or ventro-lateral the animal has to be restrained in a ventral or dorsal recumbent position with both fore and hind legs tied separately forward and backward (Newman and Anderson, 2005). If the cow may not remain standing for the duration of surgery, it may be easier to start with her recumbent rather than having her fall during the operation.

General anesthesia or heavy sedation with agents such as xylazine ( 0.03 to $0.1 \mathrm{mg} / \mathrm{Kg}$, IV) may be indicated for exceptional cases but most caesarean operations can be satisfactorily performed under local analgesia. Xylazine may increase the uterine tone, increase secretions, increase the risk of aspiration pneumonia and lead to ataxia so it must be used with caution (Le Blanc et al., 1984). The epidural infusion of xylazine has been suggested by many authors (Zuagg et al., 1990; St Jean et al., 1990; Caulkett et al., 1993) although not used widely. Paravertebral nerve block of the last thoracic and first three lumbar spinal nerves (Shah et al., 2014) provides excellent analgesia and relaxation for sub lumbar incisions, with the only reservation that it induces marked hyperemia in the muscle layers and a greater degree of hemorrhage which requires careful hemostasis (Newman and Anderson, 2005). The needle (18G, $10 \mathrm{~cm}$ long) is inserted midway between the spinous process and the tip of the transverse process and the local anaesthetic usually $2 \%$ lidocaine is injected (Shah et al., 2017). Various other nerve blocks including distal paravertebral, inverted "L" and line blocks and epidural anesthesia have been described with different success rates (Newman and Anderson, 2005).

The nerve blocks may sometimes not be properly effective and additional local infiltration anesthesia might be needed (Kuzmin, 1974). Some surgeons in fact prefer the sole use of infiltration anesthesia combined with sedation over nerve blocks.

\section{Pre-Operative considerations}

Since caesarean usually is an emergency except when it is elective, preoperative fasting is not possible (Beddard et al., 2001). Animals anaesthetized for surgery and restrained in recumbency may develop considerable ruminal tympany and regurgitate ruminal fluid during the operation (Newman and Anderson, 2005). This can be avoided if the animal is operated in a standing position. The general condition of the patient should be attached due importance before the operation is planned and animals in shock or toxemia must be given appropriate fluid replacement and/or antibiotics (Purohit and Mehta, 2006). It is often fruitful to administer the imidazole derivatives (e.g. metronidazole, tinidazole) to combat anaerobic bacteria when the fetus is emphysematous or dead since long. It is also beneficial to administer a corticosteroid preoperatively (Purohit and Mehta, 2006). Animals that have fever must also be appropriately attended before hand and analgesics must be given. Cases presented to referral centers after sufficient delay must be considered as those at potential risk and it is sometimes desirable to 
delay the operation in order to improve the general condition of the patient (Purohit and Mehta, 2006).

\section{Operative sites}

Various sites have been used for performing the operation. For a standing animal the right and the left flank laparotomies have been described to be used for cows (Newman and Anderson, 2005). The primary advantage of the left approach is that the rumen prevents evisceration of the small intestines, but rumen prolapse may occur if straining occurs during surgery. When the pregnancy is located in the right horn, some practitioners find it easier to use the right approach especially if the calf is big (Newman and Anderson, 2005). In cases in which the left approach has been used exclusively to perform several caesarean sections over time in the same cow, the practitioner may find it easier to use the right approach. For the flank approach the incision is placed in the middle of the paralumbar fossa, extending 3 to $5 \mathrm{~cm}$ ventral to the transverse process of the lumbar vertebrae to a distance of 20 to $30 \mathrm{~cm}$. A lower flank incision has also been described to be suitable for cows and buffaloes starting at $10-15 \mathrm{~cm}$ ventral to the transverse process of the lumbar vertebrae (Tyagi and Singh, 2008). A left oblique flank approach in standing cows has also been described (Parish et al., 1995). In this approach a incision is started $10 \mathrm{~cm}$ cranial and 8 to $10 \mathrm{~cm}$ ventral to the cranial aspect of the tuber coxae. The incision is extended cranioventrally at a $45^{\circ}$ angle, ending $3 \mathrm{~cm}$ caudal to the last rib. The apex of the uterine horn is more readily accessible, facilitating manipulation and exteriorization of the uterus. This incision is larger and extends more cranioventrally compared with the traditional vertical flank incision. This technique may be useful to remove large calves or when the uterine contents are contaminated (The internal abdominal oblique muscle is incised parallel to the muscle fibers; the abdominal viscera apply tension to this muscle, facilitating apposition during closure).

When the operation is to be performed in a recumbent cow the incision is either midline (over the linea alba), paramedian, low flank (Noorsdy, 1979; Newman, 2008), paramammary or oblique venterolateral (Oehme, 1967; Vaughan and Mulville, 1995; Tyagi and Singh, 2008). The paramedian incision is made between the linea alba and the subcutaneous abdominal vein extending laterally from just behind the umbilicus to the udder. The caudal deep epigastric artery, which lies on the lateral edge of the rectus abdominis muscle, should be avoided during dissection. The incision site in the paramammary approach is located between the udder and the fold of the flank. This is useful in dairy cows because it is more likely to avoid the caudal epigastric veins (and ventral edema) located on the paramedian and midline areas. The midline approach likely requires the longest incision because the linea alba is relatively inflexible. Some surgeons consider midline approach to be beneficial when an emphysematous fetus or uterine torsion is present as this minimizes the chances of abdominal contamination however; the approach carries the disadvantage of more post-operative contamination and suture dehiscence or breakage leading to hernia. The oblique ventrolateral incision is placed above the arcus cruralis in front of the stifle and extends cranioventrally in a slightly oblique direction. This approach appears to be difficult in cases of uterine torsion, in presence of an emphysematous fetus and when adhesions have formed over the uterus. However, the site has the advantage of minimal operative and postoperative complications (Purohit and Mehta, 2006).

Disadvantages of the recumbent approaches include increased surgical time and increased risks of intra-operative hemorrhage, postoperative seroma formation and incisional herniations. The increased vascularity and muscle tissues associated with the paramedian approach are thought to enhance healing and reduce incisional herniation (Noorsdy, 1979). The advantage of the midline approach is that the linea alba provides a stronger holding layer compared with the paramedian or the low oblique approach (Schultz et al., 2008). The thin facial layers with interposed muscle layers may be why the lateral approaches are more likely to herniate. There are fewer layers of closure compared with the paramedian or the low oblique approach, which reduces surgery time. Adhesions between the uterus and the body wall incision tend to be more dramatic with the ventral approaches. There are few reports in the literature for paralumbar incisional complications. Applying pressure to the opposite abdominal wall to expel intra-abdominal air during closure of the first layer also has been suggested as a means to reduce subcutaneous emphysema (Dehghani and Ferguson, 1982).

\section{Surgical technique}

Details of the surgical techniques for performing a cesarean section are well described in the literature (Turner and Mc Ilwraith, 1989; Campbell and Fubini, 1990; Frazer and Perkins, 1995; Purohit et al.,2006, Kolkman et al., 2007; Schultz et al., 2008 Purohit et al., 2013). After shaving and scrubbing with soap and water the site is scrubbed with savlon. The site is then disinfected with either chlorhexidine gluconate, povidone iodine or isopropyl alchohol (Desrochers et al., 1996). The incisions are made using a scalpel and then the skin is separated from the subcutaneous tissue by blunt dissection. The muscles (transverse and internal and external oblique abdominis muscles) and peritoneum are incised subsequently, ligating all major vessels. While incising the muscles a nick is given with a scalpel to make a small opening through the muscle, a finger is inserted under the muscle and the muscle is cut taking care of ligation of any major vessels. The muscle is separated from the underlying peritoneum by blunt dissection. The peritoneum (which is a glistening white to yellowish structure and can be easily identified by its fibers) is cut in a manner similar to that used for the muscle. The abdominal cavity is now open. The omental fat and rumen 
are deflected to one side and the uterus is located and brought to the site of incision by holding over a fetal extremity. The uterus should be packed with sterile cloth to avoid accidental spillage of uterine contents in the abdomen. The abdominal wall incision should be sufficiently large to remove the fetus safely through the abdominal wall. A small abdominal incision tends to increase the level of difficulty in removing the fetus and increases the risk of subcutaneous emphysema or seroma formation or both. However, some surgeons prefer to operate using small incisions with a view of better post-operative recovery. Sometimes it is practically impossible to bring the uterus to the operative site and pack it to prevent spillage of uterine contents in the abdomen. Surgeons have no other choice then to incise the uterus while in the abdomen. Such cases however, necessitate extra care during and after the operation. The greater curvature of the uterus should be partially exteriorized and an incision made along the greater curvature of the uterus. This incision should avoid most blood vessels and caruncles. A small uterine incision increases the risk of tearing the uterus during fetal extraction. Uterine tears most often occur at angles to the uterine incision; this increases the difficulty in closing the uterus. Under ideal circumstances, spillage of uterine contents into the abdomen should be avoided. When both legs are exteriorized (and sometimes the head if dealing with a posterior presentation), calving chains can be placed on the calf's legs to facilitate fetal extraction. While the calf is being extracted, the uterus needs to be held in place to prevent spillage of uterine contents into the abdomen. This process can be facilitated using bovine uterine grasping forceps. The umbilical cord should be stretched and ruptured in a controlled fashion by holding it adjacent to the abdominal wall. Normal retraction and contraction of the umbilical arteries may be impaired by surgical excision of the umbilical cord. If elective cesarean section is performed, careful attention should be paid to the umbilical vessels, as there is increased likelihood of excess hemorrhage because the umbilical vessels are not prepared for spontaneous rupture. Temporary clamping of the umbilical arteries and vein may be required. Umbilical complications are seen in $30 \%$ of calves delivered by cesarean section; most infections occurring in calves that required either umbilical clamping or suturing (Newman and Anderson, 2005). After the calf is removed, the veterinarian should always check for a second calf and change the gloves. If the placenta readily detaches from the caruncles, it should be removed; otherwise the veterinarian should trim the portion that is hanging outside the uterus to prevent its inclusion into the closure of the uterus. If the calf is alive and the uterus is healthy (i.e., an elective procedure), one layer of closure with absorbable suture material, such as 2 chromic catgut (Chromicgut USP 2) or vicryl (Wit et al., 1993), using a swaged-on needle is sufficient. Two-layer closure is recommended if the calf is dead or contaminated uterine fluids are suspected to be present (i.e., an emergency or emphysematous procedure), or the uterine wall is compromised or torn during fetal extraction. Closing the uterus can be facilitated by having an assistant hold the uterine horn dorsal to the uterine incision and permitting the uterus to hang down vertically-the two sides of the uterine incision are more closely opposed, facilitating suturing. Continuous inverting suture patterns, such as the Cushing, Utrecht and Lembert, can be used because they provide a tight seal, minimize suture exposure and promote healing, as the uterus heals initially by serosal-to-serosal contact (Newman and Anderson, 2005; Newman, 2008). The Utrecht pattern was the second most common clo-sure method and was typically used when uterine tis-sue did not appear compromised and a 1-layer pattern was deemed sufficient. Use of this pattern for uterine closure has been associated with improved fertility of the dam (Lyon et al., 2013). The blood clots should be removed away gently using irrigation and a gloved hand because these clots may give rise to adhesions that can affect future fertility adversely. Gauze sponges should not be used to wipe the uterus clean because this causes serosal abrasion, which increases the likelihood of detrimental uterine adhesions. Changing to new surgical gloves after the uterus is closed potentially reduces the risk of abdominal contamination. Sometimes injections of oxytocin are injected directly in the uterine wall to reduce the size of the uterus. This is necessary when the uterus is torn up to the cervical end where repair is not possible. The abdominal wall usually requires two to three layers of closure. The peritoneum and transversus are usually closed in one layer, using absorbable suture material (eg, 3 chromic catgut) in a simple continuous pattern. When the first layer is almost closed, an assistant should push on the opposite abdominal wall to push out the extra air inside the abdominal cavity. The internal and external abdominal oblique muscles are closed together using absorbable suture material $(\mathrm{eg}, 3$ chromic cat gut) in a simple continuous pattern. The internal abdominal oblique may be incorporated to the first layer when peritoneum and transversus are tearing in thin or excessively straining cows; the external abdominal oblique is then sutured alone. Polyglecaprone 25 should not be used for mucle or linea alba closure (Newman and Anderson, 2005) and the use of catgut is prohibited in some countries (Desrochers and Harvey, 2002). Excessive straining may be minimized using sedation, using an epidural and or placing a nasotracheal tube. A nasotracheal tube prevents closure of the glottis, preventing positive thoracic pressure against the diaphragm, which restricts abdominal straining. To reduce dead space and potential seroma formation, the layers can be periodically tacked down to the preceding layer. Antibiotic powder is often suggested to be sprinkled during closure of the muscle layers. The skin can be closed using either a continuous ford interlocking, simple interrupted cruciate, or simple interrupted sutures using silk or 3 polyamide (Braunamid USP 3 ). If the ford interlocking pattern is used, the current recommendation is to place several simple interrupted sutures at the base of the incision. These sutures could be removed to facilitate drainage in the event 
of an incisional infection. Sterile gauze must be tied over the skin sutures to minimize external contamination. In cases of uncorrected uterine torsions, there is some debate whether the uterus should be detorsed before or after removal of the calf during a cesarean section (Gendreau, 1947; Frazer et al., 1996). If the calf is removed first, the uterine incision if in the horn opposite the body wall incision, may make suturing the uterine incision more difficult. To exteriorize the uterus, the uterus must be manipulated to the abdominal incision. Once a fetus has been removed and the uterus can be sutured uncorrected, the torsion would be spontaneously corrected later. However, in cases presented after plenty of delay, detorsion many a times is not possible especially when the operation is performed in a recumbent animal. Occasionally during a left paralumbar fossa approach, the cow's abdominal strains prolapses the rumen through the incision, preventing exteriorization of the uterus (Newman, 2008). Using a stomach tube as a nasotracheal tube inhibits the cow from building up positive abdominal pressures, reducing rumen prolapse. The cow's position and the rumen may prevent manipulation and exteriorization of the uterus under rare circumstances, especially during a left paralumbar approach. In the most extreme cases, a rumenotomy before the hysterotomy is performed to remove sufficient rumen contents to permit completion of the cesarean section (Newman and Anderson, 2005). This option is considered as a last resort.

\section{Postoperative care}

The operative site must be cleaned daily with spirit for 3-5 days to avoid contamination. Fluid therapy may be continued for 3-5 days in cows with poor condition and cows which had an emphysematous fetus must also receive an imidazole derivative intravenously. The use, type and frequency of antibiotics vary on a case-by-case basis. The most commonly used antibiotics are penicillin $G$ procaine (Sterile penicillin G procaine; $22,000 \mathrm{U} / \mathrm{kg}$ intramuscularly every 24 hours for 3-5 days), oxytetracycline $(19.8 \mathrm{mg} / \mathrm{kg}$ intravenously, intramuscularly, or subcutaneously every 1-3 days), or ceftiofur ( $1 \mathrm{mg} / \mathrm{kg}$ intravenously, intramuscularly, or subcutaneously every 12-24 hours for 3-5 days) (Newman and Anderson, 2005). In beef cattle, florfenicol (20 mg/kg intramuscularly every 48 hours or $40 \mathrm{mg} / \mathrm{kg}$ subcutaneously every 96 hours) has been suggested. The other suggested antibiotic include amoxicillin and clavulanic acid, penicillin and streptomycin or fluroquinolone derivatives such as enrofloxacin $(7.5 \mathrm{mg} / \mathrm{kg})$, marbofloxacin $(8-10 \mathrm{mg} / \mathrm{Kg})$ or danofloxacin (6 mg/kg) (Alexander, 2013). The appropriate milk and meat withdrawal times need to be followed. If required, off-label use of antibiotics should be done cautiously and with close attention to preventing residue violations. Anti-inflammatory drugs like meloxicam, combination of diclofenac and paracetamol or flunixin meglumine $(1 \mathrm{mg} / \mathrm{kg}$ intravenously or intramuscularly every 12 hours for 2 days) may be useful to prevent abdominal adhesion formation reduce, pain and inflammation and have anti-endotoxin properties (Alexander,2013). However, a prolonged use of these drugs should be avoided as they reduce prostaglandin secretions thus delaying the uterine involution (Purohit and Mehta, 2006).

Elective or uncomplicated cesarean sections in which there is a live calf, healthy cow, healthy uterus, minimal obstetric manipulation preoperatively and minimal abdominal contamination during calf extraction likely do not require antibiotics. Antibiotics are indicated when the calf is dead, when there is a prolonged dystocia, when there is a compromised uterus, when extensive obstetric manipulations occurred preoperatively and when abdominal contamination has occurred. One report (Newman and Anderson, 2005) suggest intravenous oxytetracycline for 5 to 7 days as the antibiotic of choice when the concern for postoperative peritonitis is high (i.e., an emphysematous fetus). Standing flank incisions require little postoperative care and attention compared with ventral approaches. Cows with flank incisions often do not require stall rest that provides restricted activity and can be rebred using a bull without undue concern regarding abdominal wall herniation. In contrast, ventral approaches require strict stall rest for 6 weeks. Although these cows may be rebred using artificial insemination at 6 weeks, they should not be mounted by either their herd mates or the bull until 8 weeks after surgery, the time required to allow the ventral incisions to reach maximal holding strength.

\section{Complications}

An extensive list of preoperative, operative, postoperative and long-term complications have been reported previously (Dehghani and Ferguson, 1982). Operative complications include excessive uterine trauma, peritoneal cavity contamination, gastrointestinal trauma, excessive trauma to abdominal wall and inadequate uterine closure. Postoperative complications include peritonitis, seroma formation, retained placenta, metritis, endometritis, skin suture dehiscence, subcutaneous emphysema, adhesions, mastitis, straining cow and calf death. Long-term complications include downer cow, debilitated cows, production losses and increased calving service intervals, increased services per conception, spontaneous abortions and infertility. One study observed that $30 \%$ of the cows had poor appetite, fever, metritis, or diarrhea after cesarean section (Catell and Dobson, 1990).

\section{Prognosis}

When a cesarean section is considered an option of last resort, a negative outcome is more likely. The first 3 to 4 days post operative appear to be crucial as this is the time when most cows develop peritonitis which renders the prognosis grave and unpredictable. When a cesarean section is chosen early in dystocia cases, the procedure is more rewarding and clients are more agreeable to future cesarean sections. Cesarean section was a clinically useful method for resolving dystocia in beef cattle, providing a high 
dam survival rate and an acceptable postopera-tive fertility rate. Beef cattle producers should seek veterinary assistance whenever clinical signs of dystocia are noticed, preferably within 6 hours after onset of parturition (Heiw et al., 2018).

Categorizing the procedure as an elective, emergency (nonemphysematous) or emphysematous procedure is worthwhile because the expected outcomes and anticipated complications are dramatically different for these three situations (Newman and Anderson, 2005). It is generally accepted that the condition of the cow at the time of surgery is a major determining factor deciding outcome (Dehghani and Ferguson, 1982; Frazer and Perkins, 1995; Catell and Dobson, 1990). Cows undergoing elective cesarean sections are less likely to encounter intraoperative and postoperative complications. Cows having an emergency cesarean section are more likely to encounter intraoperative and postoperative complications (i.e., peritonitis) and are less likely to survive compared with cows that had an elective cesarean. The ideal emergency case is a dam that has been in labor briefly, with a live calf and the decision to perform a cesarean section is made quickly without prolonged obstetric manipulation by either the client or the attending veterinarian. A survey conducted in Ireland revealed that 12.7 minutes was the average (range 0-60 minutes) time spent trying to deliver a calf before deciding on surgery (Vaughan and Mulville, 1995). Another practitioner survey revealed that rapid clinical assessment was associated with improved successful outcomes (Dawson and Murray, 1992). Excessive manipulations by the owner and veterinarian alike were associated with higher postoperative complications. If the legs and the head cannot be manipulated into the birth canal, the decision to perform a cesarean section should be immediate. In beef breeds, there should be sufficient room in the pelvic canal for the calf's head and legs with space remaining to sweep an arm around the calf's shoulders to extract the fetus safely through the birth canal. If this is not possible cesarean section should be performed immediately.

The prognosis of cows that develop peritonitis remains questionable spite of rigorous therapy. Clinical signs of peritonitis are expected to occur 3 to 4 days after surgery (Campbell and Fubini, 1990; Frazer and Perkins, 1995). One practitioner survey (Vaughan and Mulville, 1995) observed that the leading cause of mortality associated with cesarean sections was peritonitis (70.3\%), followed by shock (18.1\%). Peritonitis may be caused by compromise of the uterine wall, even before surgery (Dehghani and Ferguson, 1982). Peritonitis can be caused by either exogenous (through the abdominal incision) or endogenous bacterial flora (Mijten et al., 1997a).

\section{Mortality}

A retrospective study that looked at 159 dairy cow cesarean sections found a strong correlation between cow survival and calf viability at the time of surgery (Bouchard et al., 1994). Cow survival decreased from $86 \%$ with a live calf, to $79 \%$ with a dead calf, to $33 \%$ with an emphysematous fetus.
Surgery time greater than 1 hour reduced the dam survival rate from $96 \%$ to $86 \%$ (Dawson and Murray, 1992). The most common complications associated with maternal death were peritonitis, toxemia, metritis, uterine rupture and fatty liver (Dehghani and Ferguson, 1982). Infection by Clostridium chauvoei distant to the surgery site is reportedly rare $(0.5 \%)$ and has been associated with sudden death of the cow within 24 hours of surgery (Dehghani and Ferguson, 1982).

\section{Future fertility}

When performed cautiously and when the post-operative care is sufficient, cesarean sections do not generally adversely affect the future fertility of cow. Adhesions of the uterus with surrounding structures are known to reduce future fertility. Preexisting uterine adhesions were found in $9.4 \%$ of cows compared with $31 \%$ of cows that had had a previous cesarean section (Hoeben et al., 1997). Other studies observed rates of uterine adhesions of $20 \%$ to $60 \%$ (Mijten et al., 1997a). Halsted's principles of surgery have been viewed as the mainstay of adhesion prevention (Daly, 1985). One study that looked at the complications associated with standing cesarean sections observed a significant difference between surgeons and adhesion formation (Mijten et al., 1997a). Suture type has been the subject of great debate with regard to adhesion formation. Although no advantage was observed using polyglactin 910 compared with plain catgut (Mijten et al., 1997b), synthetic materials have significant advantages over biologic material. It is generally accepted that suture exposure (especially at the knots) rather than the type of suture material is thought to be the most significant cause of adhesions along the uterine incision. Adhesion prevention includes good surgical technique, along with administration of antibiotics and nonsteroidal anti-inflammatory drugs. When appropriate, nonsteroidal anti-inflammatory drugs (i.e., flunixin meglumine or ketoprofen) and antibiotics are administered for 48 to 72 hours postoperatively. Abdominal lavage and, depending on the surgeon, a combination of heparin (40 U/ $\mathrm{kg}$ ) and potassium penicillin $\mathrm{G}(22,000 \mathrm{U} / \mathrm{kg})$, ceftiofur (1 $\mathrm{mg} / \mathrm{kg})$, or oxytetracycline hydrochloride $(200 \mathrm{mg} / \mathrm{kg}) \mathrm{mixed}$ in $500 \mathrm{~mL}$ of $0.9 \%$ sodium chloride irrigation solution and instilled into the abdomen has been used empirically to reduce adhesion formation. Applying $1 \%$ sodium carboxymethyl cellulose (CSMC) on the uterine incision and administering heparin (40 USP/kg intravenously) intraoperatively and administering heparin (40 USP/kg subcutaneously every 12 hours for 2 days) postoperatively has been suggested minimize adhesion formation.

Cesarean section in dairy cattle did not change the interval to first service or subsequent gestation length (Barkema et al., 1992b). The calving to first service was 81 \pm 29 days in dairy cattle (Cattell and Dobson, 1990). Cows having a cesarean section had an increase in services per conception and days open (Dehghani and Ferguson, 1982; Campbell and Fubini, 1990). The number of services per conception was $2.1 \pm 1.4$ for dairy cows and $1.2 \pm 0.4$ for 
beef cows (Cattell and Dobson, 1990). The calving to conception interval was $110 \pm 43$ days in dairy cattle and 99 \pm 18 days in beef cattle. No difference in the rate of abortion between cesarean sections and normal deliveries was observed (Barkema et al., 1992b). The overall pregnancy rate in dairy and beef cows that had cesarean sections has been shown to be $72 \%$ and $91 \%$ (Cattell and Dobson, 1990). These rates seem reasonable for routine cases. The lower pregnancy rates in the dairy cattle could be attributed to confounding variables, such as culling for non reproductive reasons (eg, lameness). It is generally accepted that beef cows likely tolerate surgery better with better outcomes because they are usually in better body condition and have significantly lower metabolic demands compared with high producing dairy cows. The proportion of cows and buffaloes that conceived within a year after cesarean section was 43.4\% (Purohit and Mehta, 2006). A poor future fertility was seen in cows operated in poor condition with an emphysematous fetus.

\section{Emphysematous fetus}

Removing an emphysematous fetus by fetotomy is not always a viable option, however, cesarean section is also considered to result in heavy mortalities (Bouchard et al., 1994). Cows with emphysematous fetuses should therefore be managed with intensive medical treatment, to increase the success rate. Typically, these cows are toxic, pyrexic, hypotensive and in shock. A minimal database should be collected containing a packed cell volume and total protein. Fluid therapy must be initiated usually at shock rates $(80$ $\mathrm{mL} / \mathrm{kg} / \mathrm{h}$ ) (Skarda, 1996), using either Ringer's solution or $0.9 \%$ sodium chloride. Oxytetracycline, $200 \mathrm{mg} / \mathrm{mL}(19.8$ $\mathrm{mg} / \mathrm{kg}$ every 24 hours intravenously) and flunixin meglumine, $50 \mathrm{mg} / \mathrm{mL}$ ( $1 \mathrm{mg} / \mathrm{kg}$ every 12 hours intravenously), must be administered preoperatively. A Mayo Stand Cover may be used to envelop the exteriorized uterine horn, placing the ends of the cover as deep as possible within the abdominal cavity. The cover effectively isolates the uterus from the abdominal cavity and surgical field (Newman and Anderson, 2005). "Clean" instruments must be used to close the body wall. The uterus must be extensively lavaged to remove blood clots and contaminated fluids, before the cover is removed. Changing to new gloves and, if necessary, new gowns and drapes may reduce abdominal contamination. Careful attention in closing the dead space associated with the subcutaneous layer prevents significant postoperative seroma formation.

\section{REFERENCES}

Alexander, D. (2013). Bovine caesarean section. On-farm operations. In Practice. 35: 574-588.

Barkema, H., Schukken, Y., Guard, C. (1992b). Fertility, production and culling following cesarean section in dairy cattle. Theriogenol. 38: 589-99.

Barkema, H., Schukken, Y., Guard, C., Brand, A., Vander, G.C (1992a). Cesarean section in dairy cattle: a study of risk factors. Theriogenol. 37: 489-506.
Beddard, S., Desrochers, A., Fecteau, G., Higgins, R. (2001). Comparison of four protocols for preoperative preparation in cattle. Can Vet J. 42: 199-203.

Bouchard, E., Daignault, D., Belanger, D., Coutere, Y. (1994). Cesareans on dairy cows: 159 cases. Can Vet J. 35: 770-4.

Bronislawski, S. (1950). Two methods of cesarean section in cows. Med Weter. 6: 417-18.

Campbell, M., Fubini, S. (1990). Indications and surgical approaches for cesarean section in cattle. Compend Cont Educ. 12: 285-91.

Catell, J.H., Dobson, H. (1990). A survey of caesarean operations on cattle in general veterinary practice. Vet Rec. 127: 395-9.

Caulkett, N., Cribb, P., Duke, D. (1993). Xylazine epidural analgesia for cesarean section in cattle. Can Vet J. 34: 674-6.

Daly, W.R. (1985). Wound infections. In: Textbook of veterinary surgery, [Slatter, D., editor.] second edition. Philadelphia: WB Saunders. p. 42.

Dawson, J.C., Murray, R. (1992). Caesarean sections in cattle attended by a practice in Cheshire. Vet Rec. 131: 525-27.

Dehghani, S., Ferguson, J. (1982). Cesarean section in cattle: complications. Compend Cont Educ 4: s387-92.

Desrochers, A., Harvey, D. (2002). Surgeries of the abomasum in cattle. Montreal: University of Montreal.

Desrochers, A., St. Jean, G. anderson, Rogers D.P., Chengappa, M.M. (1996). Comparative evaluation of two surgical scrub preparations in cattle. Vet Surg. 25: 336-41.

Drife, J. (2002). The start of life: A history of obstetrics. Post Grad Med J. 78: 311-15.

Dubay, B.M. (1987). Dystocia due to stenosis of pelvic outlet in a buffalo. Indian J. Anim Reprod. 8: 156.

Frazer, G.S., Perkins, N.R. (1995). Cesarean section. Vet Clin North Am Food Anim Pract. 11: 19-35.

Frazer, G.S., Perkins, N.R., Constable, P.D. (1996). Bovine uterine torsion: 164 hospital referral cases. Theriogenol. 46: 73958.

Gendreau, L.A. (1947). Cesarean section and torsion of the uterus in cows. J. Am Vet. Med. Assoc. 110: 305-07.

Hiew, M.W.H., Baird, A.N., Peter, D. Constable. (2018). Clinical signs and outcomes of beef cattle undergoing cesarean section because of dystocia. J. Am Vet. Med. Assoc. 252: 864872.

Hiew, M.W.H., Megahed, A.A., Townsend, J.R., et al. (2016). Clinical util-ity of calf front hoof circumference and maternal intrapelvic area in predicting dystocia in 103 late gestation Holstein-Frie-sian heifers and cows. Theriogenology. 85: 384-395.

Hoeben, D., Mijten, P., de Kruif, A. (1997). Factors influencing complications during caesarean section on the standing cow. Vet $Q$ 19: 88-92.

Kolkman, I., Opsomer, G., Lips, D., Lindenberg, B., de Kruif, A., Vliegher, S. De (2010b). Pre-operative and operative difficulties during bovine cesarean section in Belgium and associated risk factors. Reprod Dom Anim. 45: 1020-27.

Kolkman, I., Vliegher, S. De, Hoflack, G., Van Aert, M., Laureyms, J., Lips, D., de Kruif, A., Opsomer, G. (2007). Protocol for the cesarean section as performed in daily bovine practice in Belgium. Reprod Dom Anim. 42: 583-89. 
Kuzmin, G.N. (1974). Anesthesia in cesarean section in cows. Veterinariia. 11: 89-91.

LeBlanc, M., Hubbell, J., Smith, H. (1984). The effects of xylazine hydrochloride on uterine pressure in the cow. Theriogenol. 21: $681-90$

Lensch, J. (1958). Clinical views on cesarotomy in cattle. J Am Vet Med Assoc. 133: 205-07.

Lyons, N.A., Karvountzis, S., Knight-Jones, T.J. (2013). Aspects of bovine caesarean section associated with calf mortality, dam surviv-al and subsequent fertility. Vet J. 197: 342-350.

Mijten, P., de Kruif, A., Van der Weyden, G.C., Deluyker, H. (1997b). Comparison of catgut and polyglactin 910 for uterine sutures during bovine caesarean sections. Vet Rec. 140: 458-9.

Mijten, P., van den Bogaard, A., Hazen, M., de Kruif, A. (1997a). Bacterial contamination of fetal fluids at the time of cesarean section in the cow. Theriogenol. 48: 513-21.

Newlyn, T.A., Mostyn, H.J. (1950). Cesarean section in an ewe. Vet. Med. 45: 252-53.

Newman, K. (2008). Bovine cesarean section in the field. Vet Clin North Am Food Anim Pract. 24: 273-93.

Newman, K.D. anderson, D.E. (2005). Cesarean section in cows. Vet Clin North Am Food Anim Pract. 9: 369-88.

Nogalski, Z., Mordas, W. (2012). Pelvic parameters in HolsteinFriesian and Hersey heifers in relation to their calving. Pakistan Veterinary Journal. 32: 507-10.

Noordsy, J.L. (1979). Selection of an incision site for cesarean section in the cow. Vet Med Small Anim Clin. 74: 530-7.

Oehme, F.W. (1967). The ventro-lateral cesarean section in the cow. Vet Med Small Anim Clin. 62: 889-94.

Parish, S.M., Tyler, J.W., Ginsky, J.V. (1995). Left oblique celiotomy approach for cesarean section in standing cows. J. Am Vet Med Assoc. 207: 751-2.

Pearson, H. (1999). The cesarean operation. In: [Arthur, G.H., Noakes, D.E., Pearson, H., Parkinson, T.J. eds]. Veterinary Reproduction and Obstetrics $7^{\text {th }}$ ed Philadelphia WB Saunders co. p. 311-31.

Purohit, G.N. (2006a). Dystocia in the sheep and goats: A review. Indian J. Small Rumin. 12: 1-12.

Purohit, G.N. (2006b). Parturition related disorders in sheep and goats. Proc National Seminar on Innovations in Reproduction for Small Ruminant Production Avikanagar Jaipur. pp 227231.

Purohit, G.N., Barolia, Y., Shekhar, C., Kumar, P. (2011b). Diagnosis and correction of uterine torsion in cattle and buffaloes. Raksha Technical Review. 1(2): 11-17.

Purohit, G.N., Gaur, M., Kumar, A., Shekher, C., Ruhil, S. (2013). Perspectives of cesarean section in buffaloes. Asian Pacific J. Reprod. 2(3): 223-237.
Purohit, G.N., Gupta, A.K., Gaur, M., Bihani, D.K., Sharma, A. (2006). Periparturient disorders in goats: a retrospective analysis of 324 cases. Dairy Goat J. 84: 24-33.

Purohit, G.N., Kumar, P., Solanki, K., Shekher, C., Yadav, S.P. (2011c). Perspectives of fetal dystocia in cattle and buffaloes. Vet Sci Dev (Under Publication).

Purohit, G.N., Mehta, J.S. (2006). Dystocia in cattle and buffaloes. A retrospective analysis of 156 cases. Vet Practitioner. 7: 31-34.

Ravinder, G.K., Ravi, D., Deori, S., Pradeep, J., Pradeep, K., Gokuldas, P.P., Ahmed, S., Shah, R.H. (2008). Incomplete cervical dilation causing dystocia in a buffalo. Indian J. Vet Res. 17: 41-43.

Schultz, L.G., Tyler, J.F., Moll, D.H. (2008). Surgical approaches for cesarean section in cattle. Can Vet J. 49: 565-68.

Shah, Z., Kalhore, A.B., Kachiwal, A.B., Ahmad, I., Sattar, H. and Khan, M.A. (2014). Comparative studies on sedative and analgesic effects of xylazine and detomidine in goats. J. Anim. Plant Sci. 21(1): 1019-1023.

Shah, Z., Tunio, A.N., Ahmad, S., Ahmad, I., Ali, J. and Khan, S.B. (2017). Cesarean sections through flank incision in exotic cattle breed. Meat Sciences and Veterinary Public Health. 2(1): $1-4$.

Skarda, R.T. (1996). Local and regional anesthetic techniques: ruminants and swine. In: Lumb and Jones' Veterinary Anesthesia, third edition. [Thurman, J., Tranquilli, W., Benson, G., editors.] Baltimore: Lippincott Williams and Wilkins. p. 486-96.

Sloss, V., Dufty, J.H. (1977). Elective caesarean operation in Hereford cattle. Aust Vet J. 53: 420-4.

St. Jean G, Skarda RT, Muir WW (1990). Caudal epidural analgesia induced by xylazine administration in cows. Am J. Vet. Res. 8: 1232-6.

Tharp, V.L., Heidt, K.R., Whiteus, R.G. (1951). Correction of bovine dystocia by cesarean section and ovariohysterectomy. Vet. Med. 46: 289-90.

Turner, A.S., Mclllwraith, C.W. (1989). Bovine urogenital surgery. Techniques in Large Animal Surgery $2^{\text {nd }}$ ed Lea and Febriger Philadelphia. pp 330-32.

Tyagi, R.P.S., Singh, J. (2008). ed Ruminant Surgery. CBS Publishers and Distributors New Delhi p 284-86.

Vaughan, L., Mulville, P. (1995). A survey of bovine cesarean sections in Ireland. Irish Vet J. 48: 411-5.

Wit, F. De, Raymakers, R., Westerbeek, J., Mitjen, P., de Kruif, A. (1993). A study of uterine adhesions following suturing of the uterus with catgut or Vicryl in cesarean sections in cattle. Tijdschrift Voor Diergeneeskunde. 118: 478-79.

Young, J.H. (1944). Caesarean Section: The History and Development of the Operation From Early Times, London: H.K. Lewis and Co. Ltd.

Zuagg, J., Nussbaum, M. (1990). Epidural injection of xylazine: a new option for surgical anesthesia of the bovine abdomen and udder. Vet. Med. 85: 1043-6. 